Zanzibar, Northern Tanganyika and Uganda. Each was established in a separate glasshouse and has been so maintained since; although owing to the great production of spores and the movement of attendants between houses we cannot be sure that contamination has not occurred. Every maize family tested in the course of our brecding studies has been inoculated in two and usually all three houses. Through nearly two years and 1,600 family tests, the reaction of each individual maize family was identical, within the expected errors of experiment, in each house.

The position at the end of 1954 was therefore that we had no reason for thinking that more than one physiological race of $P$. polysora had become established in East Africa. This was supported by observations on our maize lines when tested during 1953 and 1954 in the field, in such widely separated sites as southern Tanganyika and Uganda; in general, the field behaviour corresponded with the juvenile reactions recorded in our glasshouses.

Tatle 1
\begin{tabular}{|l|c|c|c|}
\hline Origin of maize tines & $\begin{array}{c}\text { No. of sep- } \\
\text { arate families } \\
\text { tested }\end{array}$ & $\begin{array}{c}\text { Juvenile } \\
\text { reaction to } \\
\text { original race }\end{array}$ & $\begin{array}{c}\text { Juvenile } \\
\text { reaction to } \\
\text { new race }\end{array}$ \\
\hline $\begin{array}{l}\text { Selfs of AFRo 29 } \\
\text { (Colombia 2) } \\
\text { Second selfs from cross, } \\
\text { AFRO 29 } \times \text { Katumbili } \\
\text { Second selfs from cross, } \\
\text { AFR0 29 } \times \text { Durum } \\
\begin{array}{c}\text { Self of AFRO 250 } \\
\text { (Amarillo Caryotepe } \\
\text { ex Nicaragua) }\end{array}\end{array}$ & 3 & Class 01 & Class 4 \\
\hline
\end{tabular}

In January 1955, however, during routine testing of certain maize lines in our glasshouses, we obtained a reaction strongly suggesting a mixture of two physiological races of the fungus; the expected hypersensitive lesions were interspersed with a few large sori characteristic of full susceptibility. Isolations were made from the large sori and the suspected new race established. The new race was then inoculated to a number of maize lines known to behave uniformly to the original race; and simultaneous control inoculations with original-race spores were made.

In the course of these experiments we encountered some anomalies that require further study. A number of pure lines gave identical reactions to both races of the fungus. In Table 1 are shown results of experiments in which a clear differential reaction has been recorded.

The conclusion that a new race of $P$. polysora has appeared in our glasshouses seems inescapable. How it has arisen cannot be decided; but since the nearest known field occurrence of this rust is more than a hundred miles from Muguga and no newly collected material has been introduced into our houses for more than two years, it is unlikely that the new race has accidentally entered our houses from outside.

East African Agriculture and

A. K. RYLAND

H. H. STOREY

Forestry Research Organization, Muguga, Kenya Colony. May 3.

1 Storey, H. H., and Ryland, A. K., Nature, 173, 778 (1954).

"Stakman, E. C., Levine, M. N., and Loegering, W. Q., Identification of Physiologie Races of Puccinia graminis tritici, U.S.D.A. Bureau of lintomology, JE-617 (1944).

\section{A New Method for counting Live and Dead Bull Spermatozoa}

WHEN bull semen is diluted in a buffered $(p H 7 \cdot 0)$ solution of sodium chloride which is isotonic with bull seminal plasma $\left(\Delta,-0.54^{\circ}\right.$ C. $)$ and is filtered through a layer of small glass balls, the dead spermatozoa are retained by the filter while live ones pass through; it is therefore possible to estimate the percentage dead spermatozoa in bull semen by comparing the opacity of diluted semen before and after filtration.

Estimations were made on twenty-six untreated samples of bull semen and on three samples which contained different proportions of killed spermatozoa. The spermatozoa were killod by rapidly pipetting semen at $37^{\circ} \mathrm{C}$. into tubes pre-cooled to $5^{\circ}, 0^{\circ}$ and $-10^{\circ} \mathrm{C}$.

For filtration, the semen was diluted by adding a few drops $(0 \cdot 1-0 \cdot 2 \mathrm{ml}$.) of semen to $20 \mathrm{ml}$. buffered saline. In the test, $10 \mathrm{ml}$. of the suspension was pipetted gently on to the dry filter bed and the entire filtrate used for measurement. The filter bed consisted of $1.0 \mathrm{ml}$. dried acid-washed glass balls ('Ballotini', Chance Bros.; mean diameter, 200 $\mu$ ); these were held in place in a $1 \frac{1}{2}$-in. filter funnel by a single large glass ball ( $5 \mathrm{~mm}$. diameter). The upper surface of the filter bed was protected by a thin layer of large glass balls $(3 \mathrm{~mm}$. diameter) so that the bed was not disturbed when the suspension was poured on to it. The optical density of the suspensions before and after filtration was measured in a Spekker photometer (Hilger and Son) in $1-\mathrm{cm}$. euvettes.

Estimates of the proportions of dead spermatozoa in undiluted semen were made by counting the number of eosinophil spermatozoa in a total of a hundred spermatozoa from each of two smears stained with nigrosin-eosin 1 .

Statistical analysis shows a highly significant correlation $(r=0.7 ; p<0.001)$ between the percentage eosinophil spermatozoa and the percentage difference in opacity between filtered and unfiltered portions of the same sample of semen; the analysis was made by Dr. R. C. Campbell, A.R.C. Unit of Reproductive Physiology and Biochemistry, Cambridge.

Further, microscopical examination showed that the proportion of motile spermatozoa was uniformly greater in the filtrates than in the unfiltered suspensions.

Because a relationship is known to exist between the proportion of dead spermatozoa in bull semen and its fertility ${ }^{2}$, we believe that the technique we have described may form the basis of a practical test for the evaluation of bull semen used for artificial insemination.

We are grateful to Mr. L. E. A. Rowson, Cambridge Cattle Breeders, Ltd., for supplies of bull semen.

A, D. BANGHAM J. L. Hancock

Agricultural Research Council

Institute of Animal Physiology,

Babraham,

Cambridge.

May 10.

${ }^{1}$ Campbell, R. C., Hancock, J. L., and Rothschild, Lord, J. Exp. Biol., 30, 44 (1953)

${ }^{2}$ Bishop, M. W. H., Campbell, R. C., Hancoek, J. L., and Walton, A., $J$. Agric. Sci., 44, 227 (1954). 